\title{
Chemical Composition and In Vitro Activity of Plant Extracts from Ferula communis and Dittrichia viscosa against Postharvest Fungi
}

\section{Erjon Mamoci ${ }^{1,2}$, Ivana Cavoski ${ }^{2, *}$, Vito Simeone ${ }^{2}$, Donato Mondelli ${ }^{3}$, Lina Al-Bitar ${ }^{2}$ and Pierluigi Caboni $^{4}$}

1 Dipartimento di Science per l'Ambiente, Università degli Studi di Napoli "Parthenope" Centro Direzionale, Isola C4, 80143 Napoli, Italy

2 Istituto Agronomico Mediterraneo di Bari,Via Ceglie 9, 70010 Valenzano, Italy

3 Dipartimento di Biologia e Chimica Agro-Forestale ed Ambientale, Università degli Studi di Bari, Via Amendola 165/A, 70126 Bari, Italy

4 Dipartimento di Tossicologia, Università degli Studi di Cagliari, Via Ospedale 72, 09124 Cagliari, Italy

* Author to whom correspondence should be addressed; E-Mail: cavoski@iamb.it;

Tel.: +390804606365; Fax: +390804606305.

Received: 1 March 2011; in revised from: 15 March 2011 / Accepted: 18 March 2011 /

Published: 22 March 2011

Abstract: F. communis and D. viscosa are perennial Mediterranean weeds that have been used for different therapeutic purposes in traditional pharmacopeia. Plant extracts were obtained from air dried D. viscosa young shoots (DvA) and F. communis aerial part (FcA) and roots $(\mathrm{FcR})$ with $n$-hexane. The chemical compositions of the extracts were analyzed by HPLC-DAD, LC-MS (ESI) and LC-Q-TOF techniques. Two sesquiterpene lactones (inuviscolide, tomentosin) and three sesquiterpene acids (costic acid, hydroxycostic acid, ilicic acid) were identified from the $D$. viscosa extract, while in $F$. communis extracts three daucane sesquiterpenes (acetoxyferutinin, oxojaeskeanadioyl anisate, fertidin) and one coumarin (ferulenol) derivates were found. Biological activities of plant extracts were studied in in vitro experiments on the colonies and conidia of Botryotinia fuckeliana, Penicillium digitatum, P. expansum, Monilinia laxa, M. fructigena and Aspergillus spp. Extracts showed varying degree of antifungal activities on colony growth and conidia germination. The extract from FcA showed the least effect, while DvA extract had the strongest fungitoxic effects. FcR extract presented a fungitoxic effect on the colony 
growth, but it was not able to inhibit the conidia germination. These distinctions can be attributed to the differences in chemical composition of plant extracts.

Keywords: plant extracts; sesquiterpenes; coumarin; postharvest fungi

\section{Introduction}

Decay diseases caused by fungi create great postharvest losses of fruits and vegetables. Due to their attack they make the crop unfit for consumption and additionally some postharvest pathogens are able to produce mycotoxins [1-2]. Synthetic fungicides are the main measure used in the management of postharvest decay [3]. Pesticide residues [4] and development of resistant strains of fungi from the continuous application [5,6] are the major constraints to their use. Plant derived compounds are generally assumed to be more acceptable and less harmful than synthetic ones. These compounds possess a high potential for pest management since most of them are not phytotoxic, easily biodegradable and sometimes stimulatory to the host metabolism [7]. Therefore, exploitation of the new alternatives to synthetic fungicides should be considered.

Ferula communis (L.) and Dittrichia viscosa (L.) W. Greuter (syn. Inula viscosa (L.) Aiton., Cupularia viscosa G. et G.) are perennial weeds, native to the Mediterranean basin. In traditional pharmacopeia, several species of Ferula genus and D. viscosa have been used for different therapeutic purposes [8-10].

F. communis belongs to the family Umbelliferae and different chemical investigations have reported the presence of coumarinosesquiterpenes [11], daucane esters [8,12] and phenylpropanoid compounds [13] in fruits and roots. There are two distinguishable chemotypes of $F$. communis: i) the 'nonpoisonous' chemotype, containing as main constituents the daucane esters; and ii) a 'poisonous' chemotype containing prenylated coumarins, but missing the daucanes [14]. Prenylcoumarin compounds from $F$. communis (L.) were thought to be responsible for the toxic effects on sheep, goats, cattle and horses [11]. Recently the presence of the toxic prenylcoumarin ferulenol was reported in the 'non-poisonous' chemotype of $F$. communis [14,15]. Al-Yahya et al. [16] isolated three antibacterial sesquiterpenes 14-(o-hydroxycinnamoyloxy)-dauc-4,8-diene, ferulenol and ferchromone from roots of $F$. communis. Another two daucane esters, $2 \alpha$-acetyl- $6 \alpha$-(benzoyl)-jaeschkenadiol and $2 \alpha$-acetyl-6 $\alpha$-( $p$-anisoyl)jaeschkenadiol [17], and two coumarine sesquiterpenes, 2-nor-1,2-secoferulenol [18] and feselol [13], were isolated from roots, but their activities were not studied. Ferulenol isolated from the roots of $F$. communis and its derivates have shown good antimycobacterial activity [19,20], but there are no data that reports their activity on plant pathogenic fungi.

D. viscosa belongs to the family Compositae and different chemical investigations have reported the presence of flavonoids [21], triterpenoids [22,23], sesquiterpene lactones and acids [24-26]. The biological activity of this plant has been subject of different investigations. Formulated leaf extracts of D. viscosa were tested for their nematicidial activity in field trials, where only a slight effect was obtained, even though the formulated extract was effective in pot experiments [27]. D. viscosa has also been subject of investigation against insects [28] and mites [29]. A sesquiterpene lactone, tomentosin, has been isolated and identified from $D$. viscosa and it was shown to be active under in vitro conditions 
against the dermatophytes Microsporum canis, M. gypseum and Trichophyton mentagrophytes [30]. The same authors observed a greater antifungal activity of leaf extracts, due to the high levels of the sesquiterpene carboxyeudesmadiene, against dermatophytes and Candida spp. [31]. D. viscosa extract causes a decline in chitin content, a very important constituent of fungal cell wall, which probably explains the antimycotic activity of the plant extract against dermatophytes. The extract caused dramatic changes in the hyphae and spore morphology due to severe damage in the fungal cell coat [32,33]. Qasem et al. [34] reported that, D. viscosa incorporated as shoot dried material or crude water extract in a culture medium, showed antifungal effects on the mycelial growth of Fusarium oxysporum f.sp. lycopersici. Abou-Jawdah et al. [35] found out that $D$. viscosa has high activity against spore germination, but only moderate activity against mycelial growth of different fungi. Under in vivo conditions preventive sprays of $D$. viscosa on squash and cucumber seedlings gave efficient protection against Botrytis cinerea and Sphaerotheca cucurbitae, but failed to control green mold of citrus fruits caused by Penicillium sp. [35]. Extracts of $D$. viscosa made with organic solvents were effective controlling downy mildew in grape [36] and late blight in potato and tomato, downy mildew in cucumber, powdery mildew in wheat and rust in sunflower, under controlled conditions [37]. Cohen et al. [38] using an emulsified concentrate formulation of the oily paste extracts provided very good control against downy mildew of grapes caused by Plasmopara viticola. The major inhibitory compounds were identified as tomentosin and costic acid [38]. Costic acid has also been sustained to represent one of the principle nematicidal ingredients of $D$. viscosa against Meloidogyne sp. [39]. Although the antifungal activities of D. viscosa have been studied its possible application in postharvest fungi control remains unexplored.

The aim of this research was to test the in vitro antifungal activity of plant extracts from $F$. communis and D. viscosa against postharvest fungi of fruits where limited or inexistent information was available and to characterize plant extracts by HPLC-DAD, LC-MS (ESI) and LC-Q-TOF analysis.

\section{Results and Discussion}

\subsection{Extracted Yield}

Extracted yields obtained from air dried plant parts of D. viscosa young shoots (DvA), F. communis aerial part (FcA) and root (FcR) are presented in Table 1.

Table 1. Plant species, phenological phase, plant extract abbreviation and extracted yields from plant material (mean values followed by ** are significantly different at $\mathrm{P}<0.01$ according to Duncan's multiple range test).

\begin{tabular}{|l|c|c|c|}
\hline \multicolumn{1}{|c|}{ Plant species } & $\begin{array}{c}\text { Phenological } \\
\text { phase }\end{array}$ & $\begin{array}{c}\text { Plant extract } \\
\text { abbreviation }\end{array}$ & $\begin{array}{c}\text { Extracted } \\
\text { yield }(\mathbf{g} / \mathbf{k g ~ d w})\end{array}$ \\
\hline $\begin{array}{r}\text { D. viscosa } \\
\text { F. communis } \\
\text { roots } \\
\text { aerial part }\end{array}$ & $\begin{array}{c}\text { Leaf-rosette } \\
\text { Flowering }\end{array}$ & DvA & 76.4 \\
& & FcR & 79.5 \\
& & FcA & $25.1^{* *}$ \\
\hline
\end{tabular}


The highest yields of 79.5 and $76.4 \mathrm{~g} / \mathrm{kg}$ were obtained from FcR and DvA, respectively, while the yield from FcA with $25.1 \mathrm{~g} / \mathrm{kg}$, was much lower. These differences are attributed to the fact that plant secondary metabolites often accumulate in specific plant parts [40] and their quantity is related to the plant's phenological stage [41].

\subsection{Chemical Composition}

The HPLC-DAD and LC-MS (ESI) analysis of the DvA $n$-hexane soluble fraction allowed us to indentify five compounds (Figures 1 and 2; Table 2). Figure 1 shows the HPLC profiles at 206 and 254 $\mathrm{nm}$ of the DvA extract under the optimized conditions of analysis, whereas Figure 2 shows the LC-MS (ESI) profile in positive and negative modes. Table 2 lists the compounds identified with their UV absorption maxima, molecular weights and characteristic adducts. The chromatograms in Figure 1 at $206 \mathrm{~nm}$ show the presence of two main peaks tomentosin (2) and costic acid (4). Furthermore, three minor peak compounds $\mathbf{1}, \mathbf{3}, \mathbf{5}$ were found. These peaks could be identified as inuviscolide, ilicic acid and $3 \alpha$-hydroxycostic acid, respectively.

Peak 1, identified as inuviscolide, presents a $\lambda_{\max }$ at 225 and $254 \mathrm{~nm}$ and a positive and negative ESI-MS spectrum comparable with compound 2, tomentosin. Tomentosin presents a $\lambda_{\max }$ at $254 \mathrm{~nm}$, attributable to its flavonoid chromophore. The positive ESI-MS spectrum of tomentosin exhibits the signals at $m / z 231\left[\mathrm{M}-\mathrm{H}_{2} \mathrm{O}+\mathrm{H}\right]^{+}, m / z 249[\mathrm{M}+\mathrm{H}]^{+} \mathrm{m} / z$ and $271[\mathrm{M}+\mathrm{Na}]^{+}$and negative ESI-MS ion at $\mathrm{m} / \mathrm{z} 247$ [M-H] $^{-}$(Figure 2). Inuviscolide and tomentosin are sesquiterpene lactones with cytotoxic and antibacterial activities isolated from $D$. graveolens [41]. Peak 3, identified as ilicic acid (eudesmane sesquiterpene derivative) showed a $\lambda_{\max }$ at $227 \mathrm{~nm}$ and gives the positive mass signals at $\mathrm{m} / z 275$ $[\mathrm{M}+\mathrm{Na}]^{+}$and $m / z 235\left[\mathrm{M}-\mathrm{H}_{2} \mathrm{O}+\mathrm{H}\right]^{+}$and the negative signal at $m / z 251[\mathrm{M}-\mathrm{H}]^{-}$(Figure 2).

Figure 1. UV spectra at 206 and $254 \mathrm{~nm}$ of DvA with UV spectra of 1) inuviscolide, 2) tomentosin, 3) ilicic acid, 4) costic acid, 5) $3 \alpha$-hydroxy costic acid.

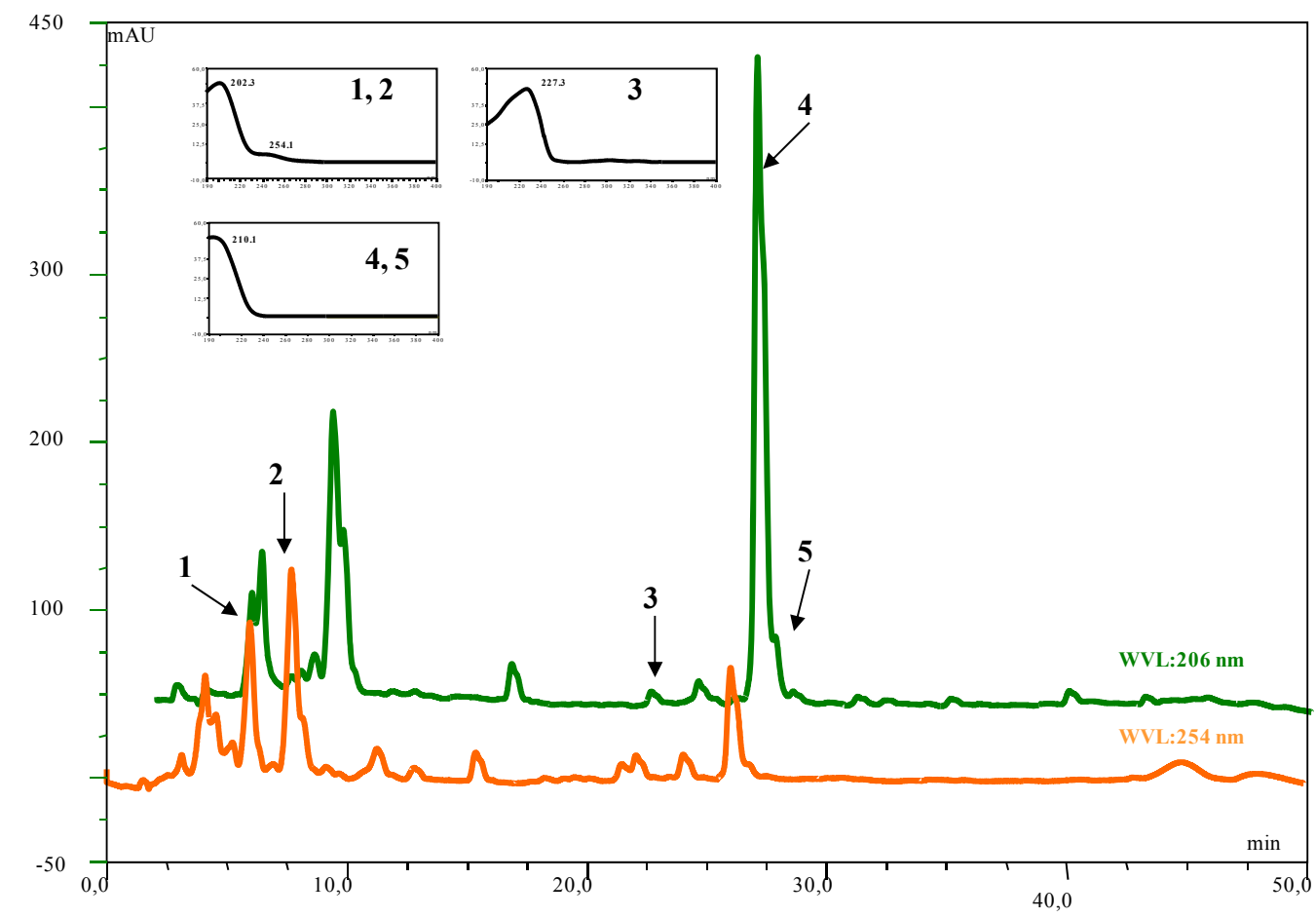


Figure 2. ESI total ion chromatogram of of DvA extract and selected ion monitoring for each compound.

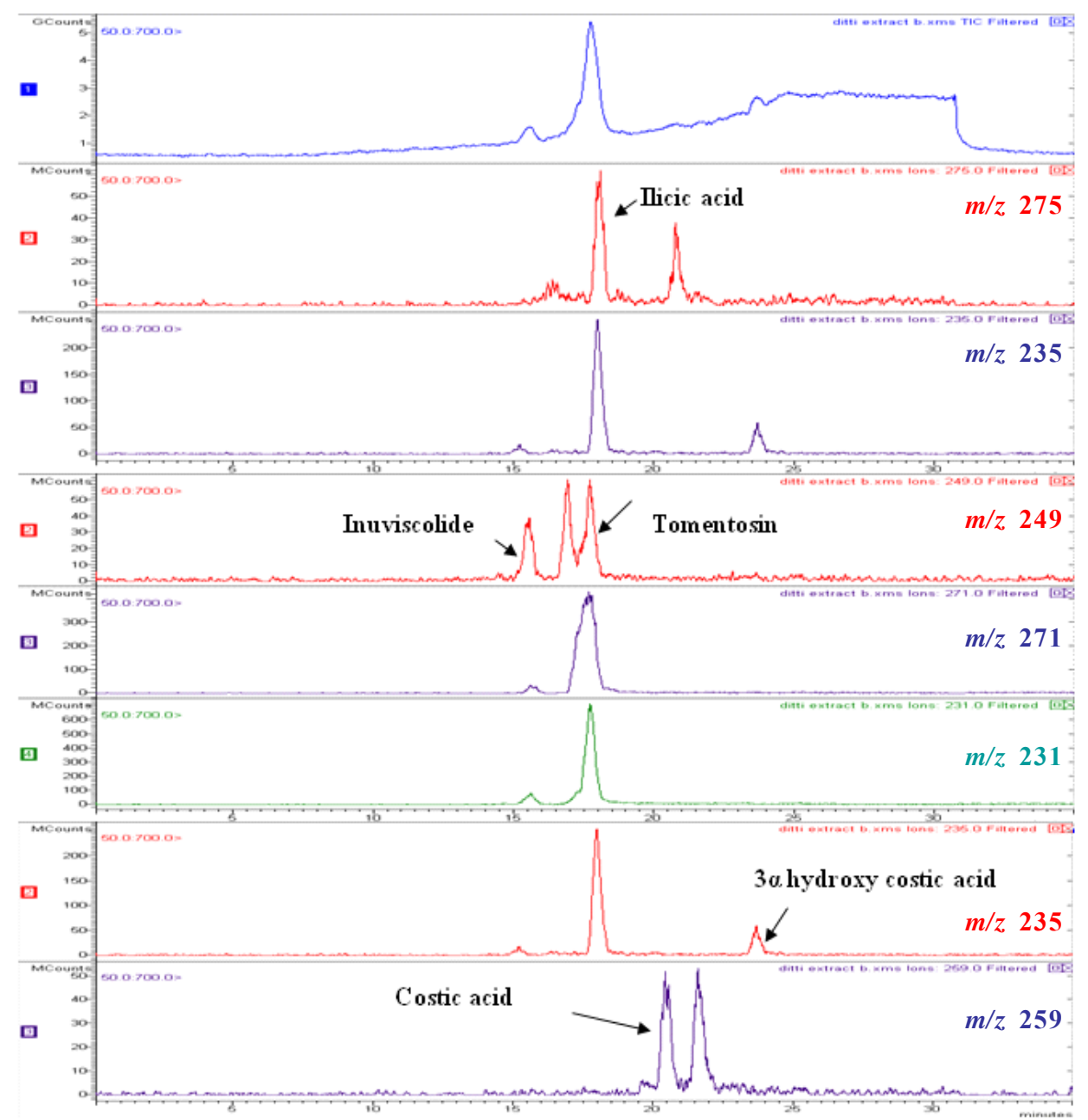

Table 2. Main signals exhibited in the HPLC-MS ${ }^{2}$ spectra of compounds detected in $D$. viscosa extract and UV Maxima $\left(\lambda_{\max }\right)$ detected in HPLC-DAD analysis and proposed attributions.

\begin{tabular}{ccccc}
\hline Compound & Number & $\lambda_{\text {max }}$ & mol. wt. & LC-MS (ESI) $\mathbf{m} / \mathbf{z}$ (amu) \\
\hline inuviscolide & 1 & 225,254 & 248 & $\begin{array}{c}231\left[\mathrm{M}-\mathrm{H}_{2} \mathrm{O}+\mathrm{H}\right]^{+} ; 249[\mathrm{M}+\mathrm{H}]^{+} ; \\
271[\mathrm{M}+\mathrm{Na}]^{+}\end{array}$ \\
\hline tomentosin & 2 & 254 & 248 & $\begin{array}{c}231\left[\mathrm{M}-\mathrm{H}_{2} \mathrm{O}+\mathrm{H}\right]^{+} ; 249[\mathrm{M}+\mathrm{H}]^{+} ; \\
271[\mathrm{M}+\mathrm{Na}]^{+} ; 247[\mathrm{M}-\mathrm{H}]^{-}\end{array}$ \\
\hline ilicic acid & 3 & 227 & 252 & $\begin{array}{c}275[\mathrm{M}+\mathrm{Na}]^{+} ; 235\left[\mathrm{M}-\mathrm{H}_{2} \mathrm{O}+\mathrm{H}\right]^{+} ; \\
251[\mathrm{M}-\mathrm{H}]^{-}\end{array}$ \\
\hline costic acid & 4 & 210 & 234 & $235[\mathrm{M}+\mathrm{H}]^{+}$ \\
\hline $3 \alpha$-hydroxycostic acid & 5 & 210 & 251 & $274[\mathrm{M}+\mathrm{Na}]^{+}$ \\
\hline
\end{tabular}


For the high resolution mass spectrometry analysis of pure standards, tomentosin and inuviscolide showed similar spectra with $[\mathrm{M}+\mathrm{H}]^{+},\left[\mathrm{M}+\mathrm{H}-\mathrm{H}_{2} \mathrm{O}\right]^{+}$and $\left[\mathrm{M}+\mathrm{NH}_{4}\right]^{+}$adducts. The ppm difference between an observed ion mass/charge and exact ion mass/charge was below 10.03 (Figure 5, Table 3).

Ilicic acid had been reported as one of the active anti-inflammatory principles of $D$. viscosa [42-43]. Costic acid (peak 4) presents a $\lambda_{\max }$ at $210 \mathrm{~nm}$ in $\mathrm{ESI}^{+}$mode at $\mathrm{m} / z 257[\mathrm{M}+\mathrm{Na}]^{+}$while its hydroxylderivative $3 \alpha$ hydroxycostic acid (peak 5) gives a signal at $\mathrm{m} / z 252[\mathrm{M}+\mathrm{H}]^{+}$(Figure 2). D. viscosa has been repeatedly studied from the chemical point of view and several sesquiterpene lactones, sesquiterpene acids and flavonoids have been isolated from specimens of diverse origins [14-19].

Table 3. Q-TOF $\left(\mathrm{ESI}^{+}\right)$characteristic of inuviscolide, tomentosin, ferunelol. *calculated by Chemdraw Pro 8.0, Cambridge Soft.

\begin{tabular}{ccccccc}
\hline Compound & $\begin{array}{c}\text { Molecular } \\
\text { formula }\end{array}$ & $\begin{array}{c}\text { r. t. } \\
\text { (min.) }\end{array}$ & $\begin{array}{c}\text { Log } \\
\mathbf{P}^{*}\end{array}$ & $\begin{array}{c}\text { Calculated } \\
\text { mass } \\
\text { (amu) }[\mathbf{M}+\mathbf{H}]^{+}\end{array}$ & $\begin{array}{c}\text { Measured } \\
\text { mass } \\
\text { (amu) }\left[\mathbf{M}+\mathbf{H}^{+}\right.\end{array}$ & $\begin{array}{c}\text { Error } \\
\text { (ppm) }\end{array}$ \\
\hline inuviscolide & $\mathrm{C}_{15} \mathrm{H}_{20} \mathrm{O}_{3}$ & 4.628 & 2.15 & 249.1485 & 249.1454 & 10.03418 \\
tomentosin & $\mathrm{C}_{15} \mathrm{H}_{20} \mathrm{O}_{3}$ & 4.775 & 1.56 & 249.1485 & 249.1477 & 3.210936 \\
ferulenol & $\mathrm{C}_{24} \mathrm{H}_{30} \mathrm{O}_{3}$ & 10.020 & 5.68 & 367.2268 & 367.2263 & 1.361556 \\
\hline
\end{tabular}

Figure 3. Spectra at 257 of FcA and FcR with UV spectra of 6) acetoxyferutinin, 7) unknown, 8) oxojaeskeanadioyl anisate, 9) fertidin and 10) ferulenol.

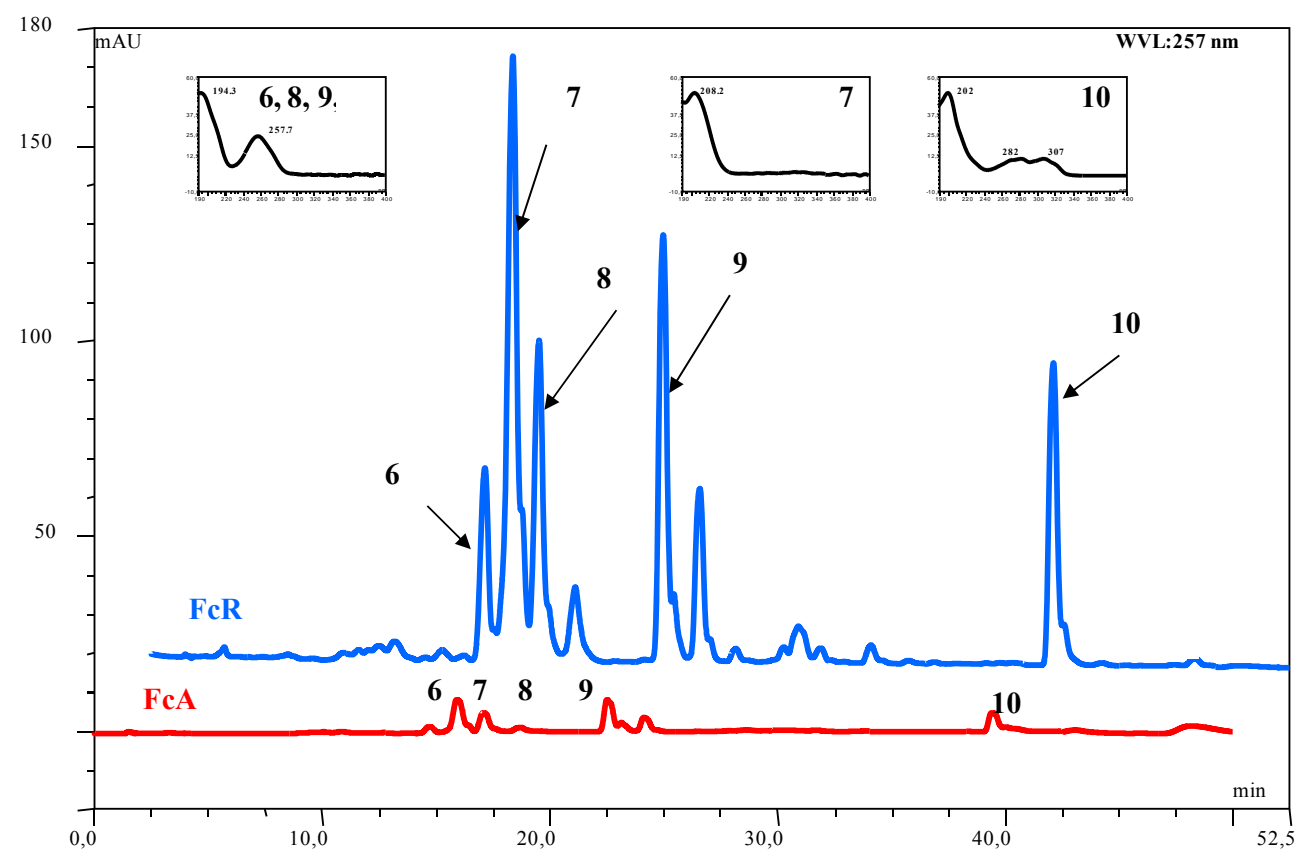

The chromatographic analysis of FcA and FcR $n$-hexane dissolved fraction allowed to identify three daucanes and one coumarin compound (Figures 3 and 4; Table 4). Figure 3 shows the HPLC-UV profile at $257 \mathrm{~nm}$ and Figure 4 illustrates the LC-MS (ESI) profile in positive mode of both FcA and FcR extracts. The chromatogram shows the presence of one main peak 7 and four other peaks 6, 8, 9 and 10 (Figure 3). Peaks 6, 8, 9 and 10 could be identified as acetoxy ferutinin, oxo-jaeskeanadiol anisate, fertidin and ferulenol, respectively. The UV spectrum of 7 presents $\lambda_{\max }$ at $208 \mathrm{~nm}$ while in 
positive and negative ESI-MS spectra no spectra were recorded because of that we could not be certain that is lapiferin. Peaks 6, 8 and 9 show UV spectrum of $\lambda_{\max }$ at $257 \mathrm{~nm}$. The ESI negative spectra of compound 6 showed a signal at $\mathrm{m} / z 415[\mathrm{M}-\mathrm{H}]^{-}$, and the ESI positive spectra of 8 and 9 compounds showed the $m / z 409[\mathrm{M}+\mathrm{Na}]^{+}$and $m / z 439\left[\mathrm{M}-\mathrm{H}_{2} \mathrm{O}+\mathrm{H}\right]^{+}$, respectively. Compounds 6,8 and 9 were, therefore, identified as acetoxy ferutinin, oxo-jaeskeanadioil anisate and fertidin, respectively (Table 4). The UV spectrum of 10 shows $\lambda_{\max } 202,282$ and $307 \mathrm{~nm}$ and the positive ESI spectra showed $[\mathrm{M}+\mathrm{H}]^{+}$ signal at $\mathrm{m} / \mathrm{z} 367$ and $[\mathrm{M}+\mathrm{Na}]^{+}$signal at $\mathrm{m} / \mathrm{z} 389$ while the $[\mathrm{M}-\mathrm{H}]^{-}$ion at $\mathrm{m} / \mathrm{z} 365$ was recorded in the negative ESI-MS spectrum (Figure 4) and was identified as ferulenol. The high resolution mass spectrometry analysis of pure standard showed only $[\mathrm{M}+\mathrm{H}]^{+}$and $\left[\mathrm{M}+\mathrm{NH}_{4}\right]^{+}$adducts (Figure 5). The ppm difference between an observed ion mass/charge and exact ion mass/charge was 1.36 (Table 3).

In the FcA extract it is evident lower signals intensity attributed to identified compound in the respect to FcR extract (Figure 4). The differences in the chemical composition between leaves, steam, roots and latex have been reported previously [15]. The components of FcA and FcR extracts were identified by comparing their HPLC retention time, UV absorption maxima and positive and negative mode fragmentation patterns to the corresponding data reported by Arnoldi et al. [14].

Figure 4. ESI total ion chromatogram of Ferula communis extracts and selected ion monitoring for each compound.

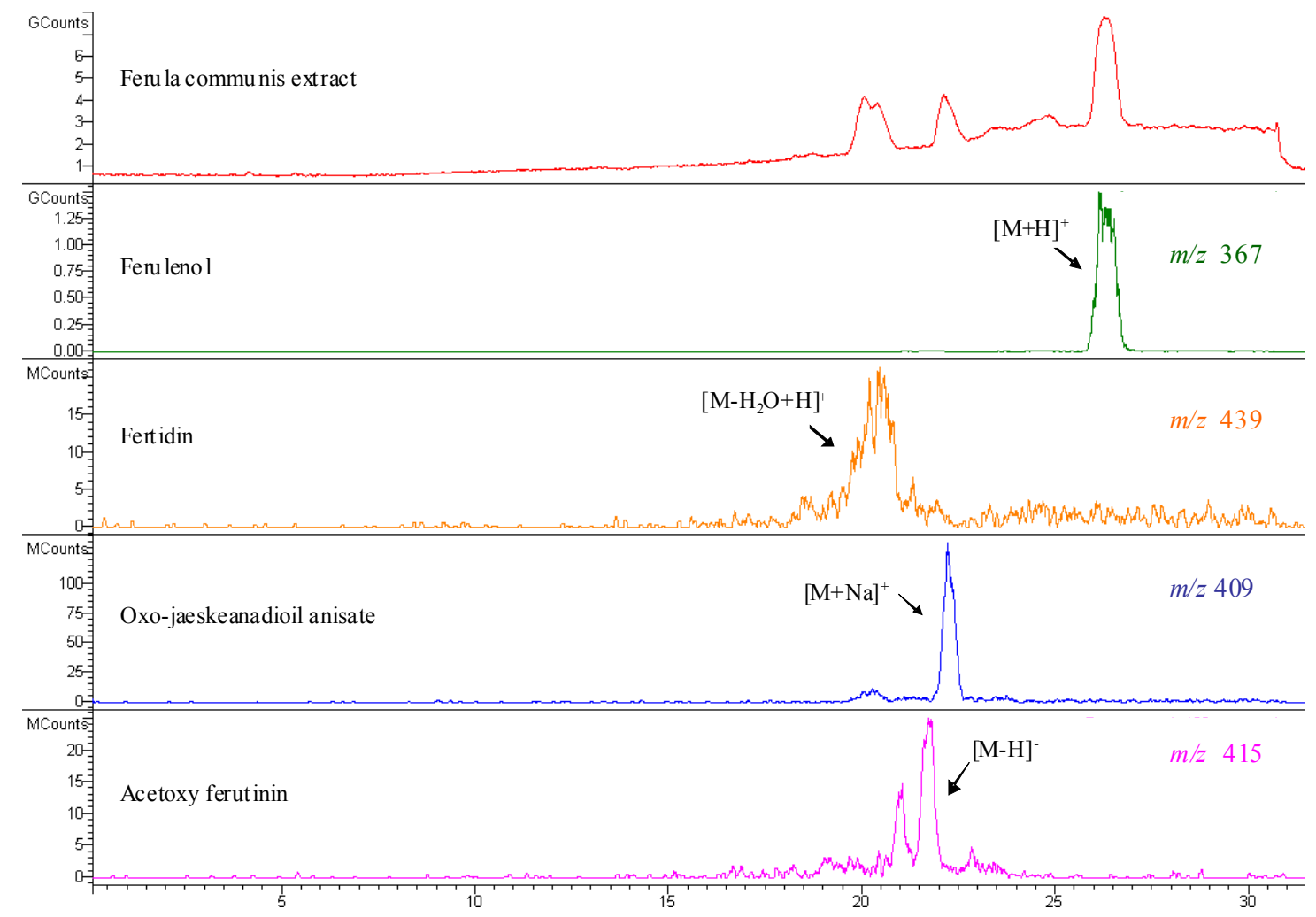


Table 4. Main signals exhibited in the HPLC-MS ${ }^{2}$ spectra of compounds detected in $F$. communis extracts and UV Maxima $\left(\lambda_{\max }\right)$ detected in HPLC-DAD analysis and the proposed attributions.

\begin{tabular}{ccccc}
\hline Compound & Number & $\boldsymbol{\lambda}_{\max }$ & $\begin{array}{c}\text { mol. } \\
\mathbf{w t .}\end{array}$ & LC-MS (ESI) $\mathbf{m} / \mathbf{z}(\mathbf{a m u})$ \\
\hline $\begin{array}{c}\text { acetoxy ferutinin } \\
\text { oxojaeskeanadioyl } \\
\text { anisate } \\
\text { fertidin }\end{array}$ & 6 & 257 & 416 & $415[\mathrm{M}-\mathrm{H}]^{-}$ \\
$\begin{array}{c}\text { ferulenol } \\
\text { f }\end{array}$ & 9 & 257 & 386 & $409[\mathrm{M}+\mathrm{Na}]^{+}$ \\
& 10 & $202,282,307$ & 366 & $\begin{array}{c}367[\mathrm{M}+\mathrm{H}]^{+} ; 365[\mathrm{M}-\mathrm{H}]^{-} ; \\
389[\mathrm{M}+\mathrm{Na}]^{+}\end{array}$ \\
\hline
\end{tabular}

Figure 5. LC-Q-TOF spectra of A) tomentosin, B) inuviscolide, C) ferulenol.
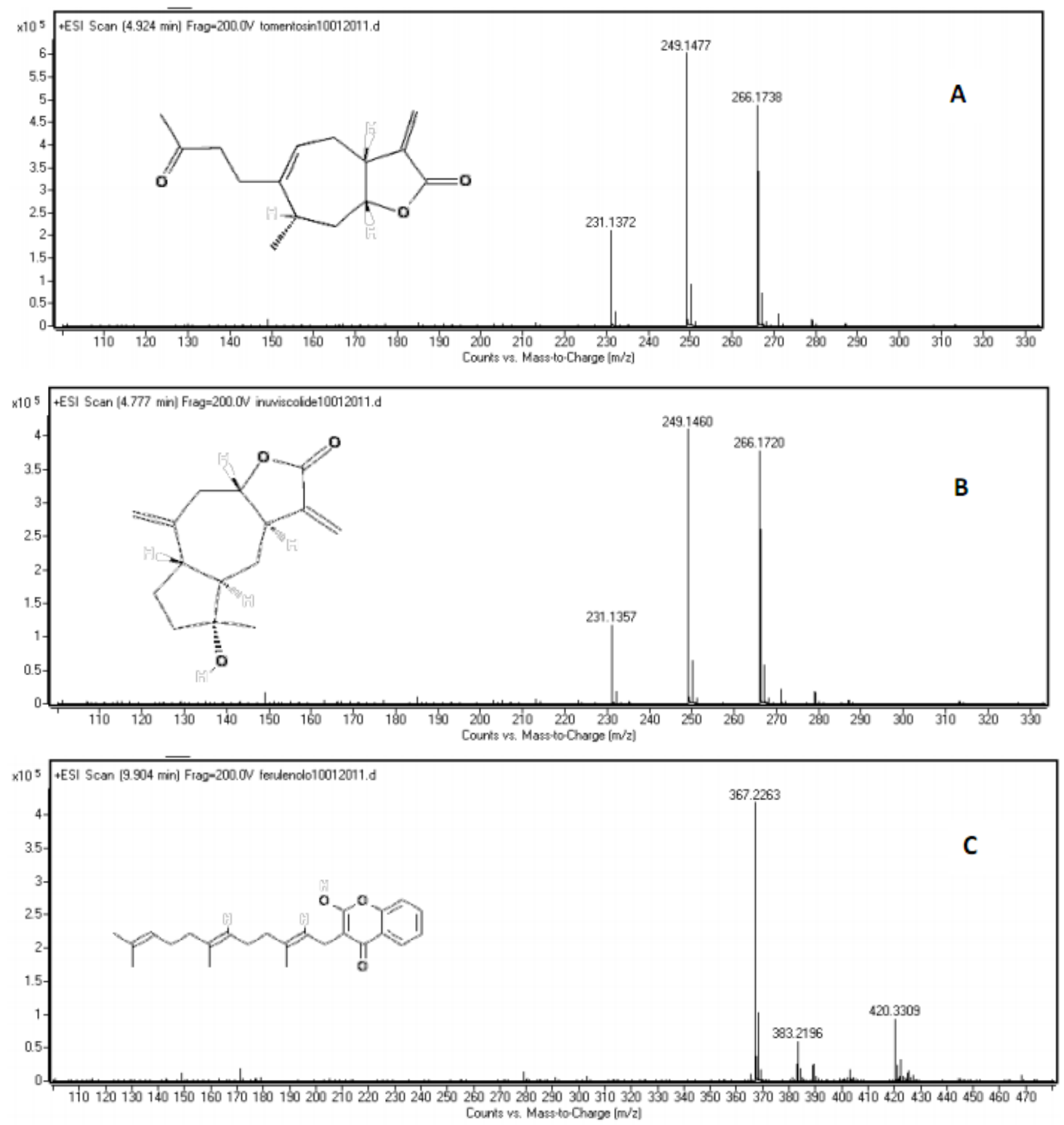
The quantity of inuviscolide and tomentosin from $D$. viscosa and ferulenol from $F$. communis extracts expressed as $\mathrm{mg} / \mathrm{g}$ of extracts are presented in Table 5.

Table 5. Content of inuviscolide, tomentosin and ferulenol in plant extracts.

\begin{tabular}{|c|c|c|c|c|}
\hline \multirow{3}{*}{ Extract } & \multicolumn{4}{|c|}{ Compounds } \\
\hline & inuviscolide & tomentosin & ferulenol & others \\
\hline & \multicolumn{3}{|c|}{ (mg/g extract) } & $(\%)$ \\
\hline DvA & 42.68 & 205.80 & - & 75.15 \\
\hline FcR & - & - & 88.40 & 91.16 \\
\hline $\mathrm{FcA}$ & - & - & 28.20 & 97.18 \\
\hline
\end{tabular}

\subsection{Antifungal Activities}

Data of $\mathrm{ED}_{50} \mathrm{~S}$ of the extracts on colony growth and conidial germination inhibitions are presented in Table 6.

Table 6. $\mathrm{ED}_{50}(\mathrm{mg} / \mathrm{L})$ and $\mathrm{MIC}(\mathrm{mg} / \mathrm{L}$, between the brackets) of the extracts on colony growth inhibitions after two (B. fuckeliana), six (P. digitatum), seven (M. laxa and $M$. fructigena), nine (Aspergillus spp. and $P$. expansum) days and conidial germination inhibitions after 10-12 h of incubations. M: colony growth; C: conidial germination; nd: not determined due to lack of inhibition; - not tested.

\begin{tabular}{|c|c|c|c|c|c|c|c|c|c|c|c|c|}
\hline \multirow{2}{*}{ Extracts } & \multicolumn{2}{|c|}{ Aspergillius spp. } & \multicolumn{2}{|c|}{ B. fuckeliana } & \multicolumn{2}{|c|}{ P. expansum } & \multicolumn{2}{|c|}{ P. digitatum } & \multicolumn{2}{|c|}{ M. laxa } & \multicolumn{2}{|c|}{ M. fructigena } \\
\hline & $\mathbf{M}$ & C & $\mathbf{M}$ & C & M & C & M & C & $\mathbf{M}$ & C & M & C \\
\hline DvA & 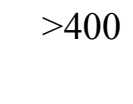 & (nd) & $\begin{array}{c}153 \\
(400)\end{array}$ & $\begin{array}{c}192 \\
(400)\end{array}$ & 0 & $\begin{array}{c}201 \\
(400)\end{array}$ & $\begin{array}{c}154 \\
(400)\end{array}$ & $\begin{array}{c}83 \\
(400)\end{array}$ & $\begin{array}{c}25 \\
(200)\end{array}$ & $\begin{array}{c}106 \\
(300)\end{array}$ & $\begin{array}{c}29 \\
(200)\end{array}$ & $\begin{array}{c}94 \\
(300)\end{array}$ \\
\hline FcR & $>400$ & nd & $\begin{array}{c}136 \\
(400)\end{array}$ & $>400$ & $>400$ & nd & $>400$ & $>400$ & $\begin{array}{c}202 \\
(400)\end{array}$ & nd & $\begin{array}{c}75 \\
(400)\end{array}$ & nd \\
\hline FcA & $>400$ & - & $>400$ & - & $>400$ & - & $>400$ & - & $>400$ & - & $>400$ & - \\
\hline
\end{tabular}

DvA was found to inhibit the colony growth of the fungi in a dose dependent manner. The highest antifungal activity of this extract was found on M. laxa and M. fructigena with $\mathrm{ED}_{50} 25.4$ and $29 \mathrm{mg} / \mathrm{L}$ respectively, followed by $B$. fuckeliana $\left(\mathrm{ED}_{50} 153 \mathrm{mg} / \mathrm{L}\right)$ and $P$. digitatum $\left(\mathrm{ED}_{50} 154 \mathrm{mg} / \mathrm{L}\right)$. The lowest antifungal activity of this extract was found on Aspergillus spp. and on P. expansum and calculated $\mathrm{ED}_{50} \mathrm{~S}$ were higher than the range of the used concentrations. DvA extract showed inhibition of conidial germination of all tested fungi. The $\mathrm{ED}_{50} \mathrm{~s}$ of $371,192,201,83,106$ and $94 \mathrm{mg} / \mathrm{L}$ were calculated for Aspergillus spp, B. fuckeliana, P. expansum, P. digitatum, M. laxa and M. fructigena, respectively. DvA demonstrated relatively high activity on conidia germination but very low activity on colony growth inhibition of Aspergillus spp. and P. expansum. These results confirm the results found by Abou-Jawdah et al. [35] where extracts of $D$. viscosa showed high activity against spore germination but only moderate activity against mycelial growth. There are different publications that demonstrate the activity of D. viscosa extracts against dermatophytes [30-33] and fungal pathogens [35,45-46] under in vitro conditions. However, there are no data that reports activities of $D$. viscosa extract on M. laxa and M. fructigena, even though in our experimental conditions it showed the highest 
effects. FcR show very low activity on the colonies of Aspergillus spp., P. expansum and P. digitatum whereas, on colony growth of M. fructigena, B. fuckeliana and M. laxa it was found to have a good fungitoxic effect with $\mathrm{ED}_{50}$ of 75, 135 and $202 \mathrm{mg} / \mathrm{L}$, respectively. No inhibitory activity of FcR was found on conidial germination in all tested fungi. FcA extract showed neglected inhibitory activity on tested fungi regarding colony growth inhibition under our experimental conditions. Therefore, the activity of this extract was not tested against the conidial germination. MICs values in most cases were of $400 \mathrm{mg} / \mathrm{L}$ except for M. laxa and M. fructigena of 200 and $300 \mathrm{mg} / \mathrm{L}$ for mycelia and conidia, respectively. In the case of Aspergillus spp. at $400 \mathrm{mg} / \mathrm{L}$ only $90 \%$ of mycelia growth inhibition was archived and MIC was not determined.

Principal component analysis (PCA) on the colony growth inhibitions and cluster analysis separate extracts into four different groups (Figure 6). Figure 6 shows that the principal components PC1 and PC2 accounted for $98.51 \%$ of the variation. Based on PCA and cluster analysis, I group contains DvA 3,4, FcR extracts, II DvA 2, 6, FcR 2,3, III DvA 1, FcA 2,4, FcR 1,6 and IV DvA 5, FcA 3, 5, 6, FcR 5 (Figure 6).

Figure 6. Classification of plant extracts according to colony growth of six postharvest fungi by PCA and cluster analysis. The percentage of total variance explained by each axis in PCA is shown. Numbers from 1 to 6, represent the pathogens Aspergillus spp., $B$. fuckeliana, M. laxa, M. fructigena, P. expansum and P. digitatum, respectively.
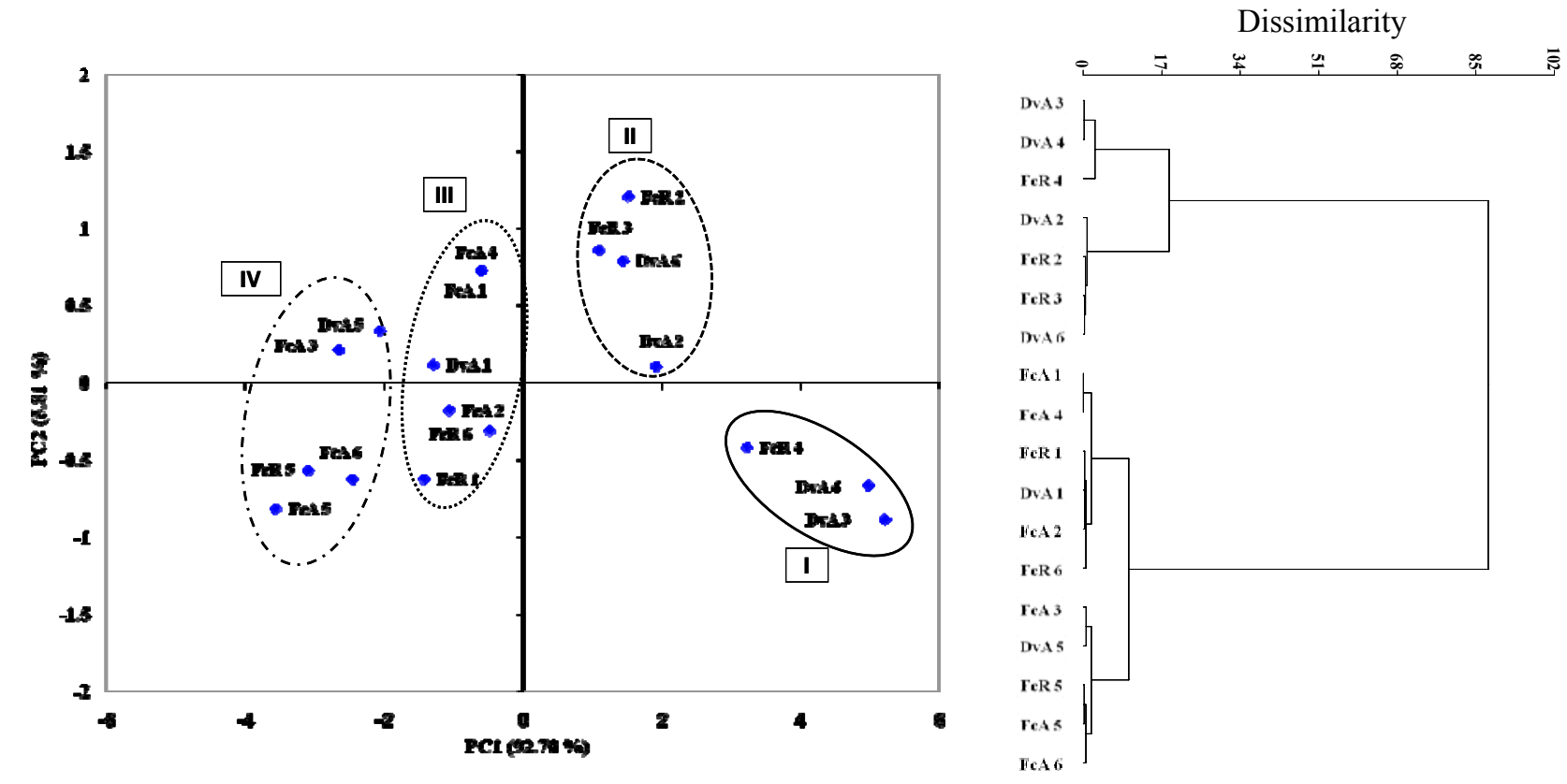

The activity of plant extracts on conidial germination clearly distinguishes three different groups (Figure 7). Each one occupied very different ordinal spaces, indicating that inhibition differed substantially among the treatments. Figure 7 shows that the principal components PC1 and PC2 accounted for $96.15 \%$ of the variation. Based on PCA and cluster analysis, there are three different groups: I DvA 6 (main inhibition), II DvA 1 to 5 (intermediate) and III FcR 1 to 6 (minor inhibition) (Figure 7). The effectiveness on colony growth and conidial germination varied among the extracts and tested fungi based on PCA and cluster analysis. 
Figure 7. Classification of plant extracts according to conidia germination of six postharvest fungi by PCA and cluster analysis. The percentage of total variance explained by each axis in PCA is shown. Numbers from 1 to 6, represent the pathogens Aspergillus spp., B. fuckeliana, M. laxa, M. fructigena, P. expansum and $P$. digitatum, respectively.
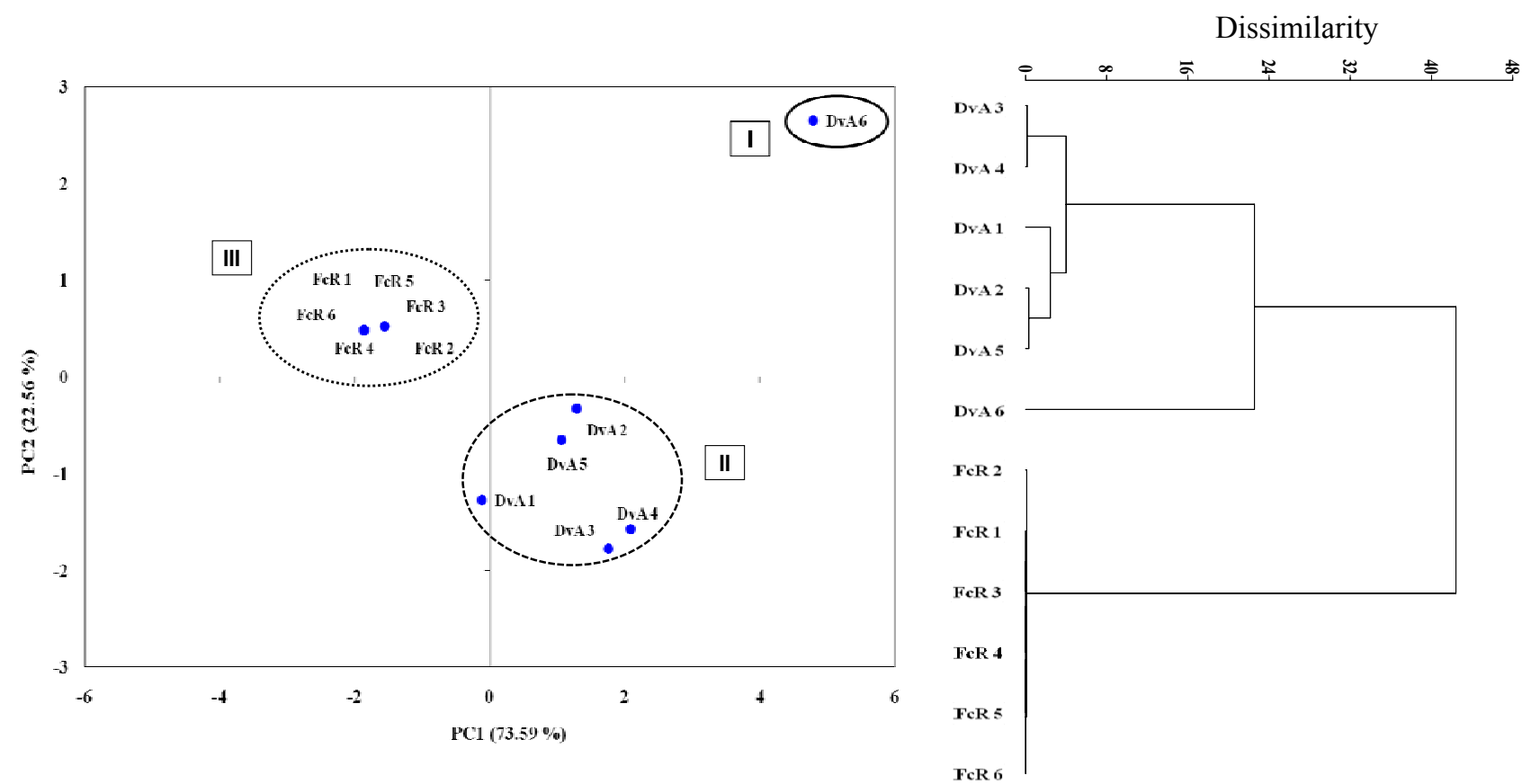

\section{Experimental}

\subsection{Plant Material and Extraction}

Plants were collected from rural areas in Apulia Region, south Italy. F. communis (L.) (Giant fennel) was collected during the flowering season and D. viscosa (L.) W. Greuter (False yellow head), during the leaf-rosette phenological phase. A voucher specimen was deposited at the Herbarium of the Botany Department, University of Bari. All samples were ground by a blade mill to a fine powder before extraction. Oleoresins were obtained by $n$-hexane extraction in a Soxhlet apparatus. Five grams of samples were extracted with $120 \mathrm{~mL} n$-hexane for 6 hours at $68^{\circ} \mathrm{C}$ with $20 \mathrm{~min} / \mathrm{cycle}$. At the end of extraction process, solvent in the flask was separated from the oleoresins by evaporation at $40{ }^{\circ} \mathrm{C}$ overnight. The content of oleoresin was corrected according to the dry weight of samples at $105{ }^{\circ} \mathrm{C}$ for 24 hours (till constant weight). Extracts were stored in a freezer at $-20{ }^{\circ} \mathrm{C}$ until use.

\subsection{Materials}

Sterile plastic Petri dishes used for in vitro antifungal trials were purchased from Barloworld Scientific Ltd (Stone, Stafordshire, UK). Organic solvents methanol and acetonitrile (HPLC grade) were purchased from Carlo Erba (Rodano, Milano Italy), whereas Tween 80 and $n$-hexane (99\% of purity) were obtained from Sigma-Aldrich (Steinheim, Germany). The filter papers, Whatman No. 1, were purchased from Baker (Mallinckrodt Baker, The Netherlands), potato dextrose agar (PDA), potato dextrose broth (PDB) and glucose from Oxoid LTD (Basingstore, Hampshire, UK). The filter paper (Miracloth) and Thoma counting chamber used for conidia suspension preparation were 
purchased from Calbiochem (California, USA) and HGB Henneberg-Sander GmbH (Lutzellinden, Germany), respectively. Standards of inuviscolide, tomentosin and ferulenol were kindly provided by Dr. Azucena González-Coloma (Instituto de Ciencias Agrarias, ICA-CSIC, Madrid, Spain).

\subsection{HPLC-DAD Analysis}

The Ultimate 3000 HPLC system (Dionex, Germering, Germany) was equipped with a photodiode array detector, fluorescence detector (FR 2000), Ultimate 3000 low pressure pump pump, Rheodyne (Rheodyne, USA) $20 \mu \mathrm{L}$ injector loop, Acclaim C18 reverse phase column $(150 \times 4.6 \mathrm{~mm} ; 3 \mu \mathrm{m})$ and Acclaim C18 reverse phase precolumn $(10 \times 4.6 \mathrm{~mm} ; 5 \mu \mathrm{m})$ and a column oven. The HPLC was controlled by and data were elaborated using the Chromeleon Software vs 6.8 (Dionex, Germering, Germany). The gradient profile for the separation of $F$. communis and D. viscosa extracts was as follows: starting from acetonitrile/water $(45: 55, \mathrm{v} / \mathrm{v})$ for $5 \mathrm{~min}$, then linear gradient to $15 \%$ water in $40 \mathrm{~min}$, maintained for $5 \mathrm{~min}$ at acetonitrile/water $(85: 15, \mathrm{v} / \mathrm{v})$ and equilibrated for $5 \mathrm{~min}$ with acetonitrile/water $(45: 55, \mathrm{v} / \mathrm{v})$ at a flow rate of $1 \mathrm{~mL} / \mathrm{min}$. Analyses were performed at UV wavelengths of 197, $254 \mathrm{~nm}$ for F. communis extracts and 206, $257 \mathrm{~nm}$ for D. viscosa extract and PDA detection range was 190-400 nm. The external calibrations were provided, and the standard calibration curves were constructed by plotting concentration against peak area. Good linearities were achieved for inuviscolide, tomentosin and ferulenol between 0.01 and $5 \mathrm{mg} / \mathrm{L}$, with a correlation coefficient of 0.9999 .

\subsection{HPLC/ESI-MS/MS Analysis}

A Varian tandem mass spectrometer (Palo Alto, CA, USA) consisting of a ProStar 410 autosampler, two ProStar 210 pumps and a $1200 \mathrm{~L}$ triple quadrupole mass spectrometer equipped with an electrospray ionization source was used to analyze the plant extracts. Varian MS workstation, version 6.7 software was used for data acquisition and processing. Chromatographic separation was performed on an XDB column $(2.1 \times 250 \mathrm{~mm}$ I.D., particle size $5 \mu \mathrm{m}$, Milford, MA). The mobile phase consisted of (A) acetonitrile and (B) bidistilled water with $0.1 \%$ of formic acid. Elution started with acetonitrile/water (10:90, v/v) reaching acetonitrile/water (100:0, v/v) in $20 \mathrm{~min}$ and hold to $25 \mathrm{~min}$ than equilibration time for $10 \mathrm{~min}$ till acetonitrile/water $(10: 90, \mathrm{v} / \mathrm{v})$. The mobile phase, previously degassed with high-purity helium, was pumped at a flow rate of $0.3 \mathrm{~mL} / \mathrm{min}$ and the injection volume was $10 \mu \mathrm{L}$. The electrospray ionization-mass spectrometer was operated in the positive ion mode. The electrospray capillary potential was set to $50 \mathrm{~V}$, while the shield was at $225 \mathrm{~V}$. Nitrogen at 49 mTorr was used as a drying gas for solvent evaporation. The atmospheric pressure ionization (API) housing and drying gas temperatures were kept at 50 and $380{ }^{\circ} \mathrm{C}$, respectively. The scan time was $1 \mathrm{~s}$, and the detector multiplier voltage was set to $1500 \mathrm{~V}$, with an isolation width of $\mathrm{m} / \mathrm{z} 1.2$ for quadrupole 1 and $\mathrm{m} / \mathrm{z}$ 2.0 for quadrupole 3. ESI mass spectra were acquired modes by scanning over the $50-700$ mass range.

\subsection{HPLC-MS Q-TOF Analysis}

The extract was analyzed by reverse phase HPLC on an Agilent 1200 series HPLC system fitted with microchip technology column (Agilent, Zorbax $300 \mathrm{SB}-\mathrm{C} 185 \mu \mathrm{m}, 43 \mathrm{~mm} 75 \mu \mathrm{m}$ ). The HPLC conditions were as follows: flow rate, $0.4 \mu \mathrm{L} / \mathrm{min}$; solvent $\mathrm{A}, 0.1 \%$ formic acid in water; solvent $\mathrm{B}$, 
methanol; gradient, solvent B $20-100 \%$ over $10 \mathrm{~min}$ and kept at $100 \%$ for $5 \mathrm{~min}$. Then $2 \mu \mathrm{L}$ of the extract dissolved in methanol-water $(80: 20, \mathrm{v} / \mathrm{v})$, was analyzed by ESI in positive mode using an Agilent 6520 time-of-flight (TOF) MS. Mass spectral data were acquired in the range $m / z 100-1000$, with an acquisition rate of $1.35 \mathrm{spectra} / \mathrm{s}$, averaging 10,000 transients. The source parameters were adjusted as follows: drying gas temperature $250 \mathrm{C}$, drying gas flow rate $5 \mathrm{~L} / \mathrm{min}$, nebulizer pressure 45 psi, and fragmentor voltage $150 \mathrm{~V}$. Data acquisition and processing were done using Agilent Mass Hunter Workstation Acquisition v. B.02.00 software.

\subsection{Isolates and Conidial Suspension Preparation}

Isolates of M. laxa, M. fructigena, B. fuckeliana, P. digitatum, P. expansum and Aspergillus spp. used in these experiments were kindly provided by Prof. Antonio Ippolito from the current collection of the Plant Protection and Applied Microbiology Department, Faculty of Agriculture, University of Bari, Italy. Conidia, obtained from 7-day-old cultures B. fuckeliana, P. digitatum, P. expansum Aspergillus spp. grown on PDA and $M$. laxa and $M$. fructigena grown on peach infected fruits with $12 \mathrm{~h} /$ day exposure to a combination of two daylight (Osram, L36W/20) and 2 near-UV (Osram, L36/73), were collected by scraping the surface of the colonies and fruits, suspended in sterile water containing $0.05 \%$ Tween 20 and filtered through Miracloth to remove mycelium fragments. The spore concentrations were adjusted by Thoma counting chamber.

\subsection{Colony Growth Inhibition Test}

The effect of plant extracts postharvest fungi was tested using a food poison technique. Aliquots of plant extracts diluted in methanol were added to the autoclaved culture medium PDA, when the temperature of the medium was $50{ }^{\circ} \mathrm{C}$, to reach final concentration of $5,10,50,100,200,300$ and $400 \mathrm{mg} / \mathrm{L}$. Final concentration of methanol didn't exceed $0.5 \%$. To increase the dispersion of extracts $0.1 \%$ of Tween 80 was added. Control in this test was PDA with $0.5 \%$ of $\mathrm{MeOH}$ and $0.1 \%$ of Tween $80.13 \mathrm{~mL}$ of testing and control solutions were added to Petri dishes. All treatments were performed in five replicates. Colony growth inhibition tests were performed by placing $6 \mathrm{~mm}$ mycelia agar disks, cut from the margin of expanding fungal colonies, in the centre of Petri dishes. The colony diameters were measured after different periods of incubation in the incubation chamber at $23{ }^{\circ} \mathrm{C}$ in the dark. The first reading was taken when the colony diameter in control reached the border of Petri dish. The first readings were taken after two (B. fuckeliana), six ( $P$. digitatum), seven (M. laxa and $M$. fructigena), nine (Aspergillus spp. and $P$. expansum) days of incubation because the hyphal growth and colony formation of fungi depend of fungal species.

\subsection{Conidial Germination Test}

Aliquots of plant extracts diluted in methanol were added to the autoclaved culture medium potato dextrose broth (PDB). The conidia concentration of each fungus $100 \mu \mathrm{L}\left(6 \times 10^{5} \mathrm{~mL}\right)$ with $900 \mu \mathrm{L}$ of PDB (200 g of potato, $10 \mathrm{~g}$ of dextrose in $1 \mathrm{~L}$ distilled water) were mixed thoroughly to reach final concentration of $10,50,100,200,300$ and $400 \mathrm{mg} / \mathrm{L}$ of plant extracts and a final concentration of conidia $6 \times 10^{4} \mathrm{~mL}$. Final concentration of methanol didn't exceed $0.3 \%$. To increase the dispersion of 
extracts $0.1 \%$ of Tween 80 was added. Control in this test was PDB with $0.3 \%$ of methanol and $0.1 \%$ of Tween 80. To carry out the test, Petri dishes of $90 \mathrm{~mm}$ were used, a sterile filter paper was placed in each plate dripping $2 \mathrm{~mL}$ of sterile distilled water. A slide was fixed with the help of plastic supporter in the Petri dish. For each treatment two Petri dishes were prepared. In each slide two drops of $20 \mu \mathrm{L}$ for each concentration were placed. After 10-12 hours at $23 \pm 1{ }^{\circ} \mathrm{C}$ of incubation at dark conditions, the percentage of spore germination was determined microscopically at $\mathrm{x} 40$ magnification by counting 100 spores in each drop. Conidia were considered to have germinated when germ tube length was greater than the width of the conidium.

\subsection{Statistical Analysis}

One-way analysis of variance (ANOVA) of yielded extracts was used to determine the statistical significance; P-values $<0.01$ were considered significant. The means were separated by Duncan's multiple range test. The data were statistically analyzed using the software package STATISTICA 6, StatSoft Inc, Tulsa, USA. Also a principal component analysis (PCA) and cluster analysis was used to discriminate the main groups of extracts on the different fungi. The probit-analysis method was used to analyze the mean data of percentage inhibition of colony growth and conidia germination relative to concentration of each plant extracts. Percentage inhibition data were transformed to probit inhibition data. The regression lines of probit inhibition against log concentration were obtained and the effective concentration $50\left(\mathrm{ED}_{50}\right)$ was calculated in $\mathrm{mg} / \mathrm{L}$ according to linear model. Means were plotted against $\log _{10}$ values of the extract concentrations. MIC (minimum inhibitory concentration) was considered as the least concentration of plant extracts that does permit any visible growth of the inoculated mycelia or conidia during the incubation.

\section{Conclusions}

Results indicate that $D$. viscose possesses higher antifungal activity in comparison with that of $F$. communis, where information on its antifungal activity is limited or inexistent. F. communis root extract only affected colony growth of B. fuckeliana, M. laxa and M. fructigena and no inhibitory effects were observed on conidial germination under applied experimental concentrations. F. communis aerial part extract showed a lack of activity on colony growth and was not tested on conidia.

As expected, D. viscosa extract demonstrated high activity on colony growth of most tested fungi, except Aspergillus spp. and $P$. expansum. In addition it posses the best effect on conidia germination of $M$. laxa and $M$. fructigena where data are still lacking. The extract of $D$. viscosa could be a potential alternative for the control of fungal rotting of fruits but further in vivo studies should be done.

Different degrees of antifungal activities can probably be explained by the varied chemical composition of the tested plant extracts. It seems that sesquiterpene lactones and acids from $D$. viscosa were more active than the daucane sesquitepenes and coumarin from $F$. communis against postharvest fungi. Antifungal activity can be associated with the compounds that occurred in extracts but the activities of pure compounds should be examined. 


\section{Acknowledgments}

The authors like to express their special thanks to Azucena González-Coloma (Instituto de Ciencias Agrarias, ICA-CSIC, Madrid, Spain) for providing the standards of inuviscolide, tomentosin and ferulenol, to Antonio Ippolito (DPPMA, Università degli Studi di Bari) for providing the fungi isolates, to ssa Giorgia Sarais (Dipartimento di Tossicologia, Università degli Studi di Cagliari) for LC-MS (ESI) analysis and Teodoro Miano (DIBCA, Università degli Studi di Bari) for reviewing the article and useful suggestions.

\section{References and Notes}

1. Moss, M.O. Mycotoxins review-1. Aspergillus and penicillium. Mycologist 2002, 16, 116-119.

2. Phillips, D.J. Mycotoxins as a postharvest problem. Postharvest Pathology of Fruits and Vegetables: Postharvest Losses in Perishable Crops; Moline, H. E., Ed.; Agricultural Experimental Station, University of California Berkeley Publications: Berkeley, CA, USA, 1984, pp. 50-54.

3. Ippolito, A.; Nigro, F. Impact of preharvest application of biological control agents on postharvest diseases of fresh fruits and vegetables. Crop Prot. 2000, 19, 715-723.

4. Schirra, M.; D'Aquino, S.; Palma, A.; Marceddu, S.; Angioni, A.; Cabras, P.; Scherm, B.; Migheli, Q.. Residue level, persistence, and storage performance of citrus fruit treated with fludioxonil. J. Agric. Food Chem. 2005, 53, 6718-6724.

5. Rosenberger, D.A.; Wicklow, D.T.; Korjagin, V.A.; Rondinaro, S.M. Pathogenicity and benzimidazole resistance in Penicillium species recovered from flotation tanks in apple packinghouses. Plant Dis. 1991, 75, 712-715.

6. Baraldi, E.; Mari, M.; Chierici, E.; Pondrelli, M.; Bertolini, P.; Pratella, G.C. Studies on thiabendazole resistance of Penicillium expansum of pears: pathogenic fitness and genetic characterization. Plant Pathol. 2003, 52, 362-370.

7. Mishra, A.K.; Dubey, N.K. Evaluation of some essential oils for their toxicity against fungi causing deterioration of stored food commodities. Appl. Environ. Microbiol. 1994, 60, 1101-1105.

8. Gonzalez, A.G.; Barrera, J.B. Chemistry and source of mono- and bicyclic sesquiterpenes from Ferula species. Nat. Prod. Rep. 1995, 64, 1-92.

9. Ali-Shtayeh, M.S.; Yaghmour, R.M.R.; Faidi, Y.R.; Salem, K.; Al Nuri, M.A. Antimicrobial activity of 20 plants used in folkloric medicine in the Palestinian area. J. Ethnopharmacol. 1998, 60, 265-271.

10. Lev, E.; Amar, Z. Ethnopharmacological survey of traditional drugs sold in Israel at the end of the 20th century. J. Ethnopharmacol. 2000, 72, 191-205.

11. Appendino, G.; Tagliapietra, S.; Gariboldi, P.; Nano, G.M.; Picci, V. Oxygenated prenylated coumarins from F. communis. Phytochemistry 1988, 27, 3619-3624.

12. Valle, M.G.; Appendino, G.; Nano, G.M.; Picci, V. Prenylated coumarins and sesquiterpenoids from F. communis. Phytochemistry 1987, 26, 253-256.

13. Miski, M.; Jakupovic, J. Cyclic farnesyl-coumarin and fernesyl-chromone derivatives from $F$. communis subsp. communis. Phytochemistry 1990, 29, 1995-1998. 
14. Arnoldi, L.; Ballero, M.; Fuzzati N.; Maxia, A.; Mercalli, E.; Pagni, L. HPLC-DAD-MS identification of bioactive secondary metabolites from Ferula communis roots. Fitoterapia 2004, $75,342-354$.

15. Rubiolo, P.; Matteodo, M.; Riccio, G.; Ballero, M.; Christen, P.; Fleury-Souverain, S.; Veuthey, J. L.; Bicchi, C. Analytical discrimination of poisonous and nonpoisonous chemotypes of giant fennel (Ferula communis L.) through their biologically active and volatile fractions. J. Agric. Food Chem. 2006, 54, 7556-7563.

16. Al-Yahya, M.A.; Muhammad, I.; Mirza, H.H.; El-Feraly, S.F. Antibacterial constituents from the rhizomes of Ferula communis. Phytother. Res. 1998, 12, 335-339.

17. Miski, M.; Mabry T.J. Daucane esters from F. communis subsp. communis. Phytochemistry 1985, 24, 1735-1741.

18. Appendino, G.; Tagliapietra, S.; Crarotto, G.; Nano, G.M. Structure and synthesis of a prenylated acetophene from F. communis. Gazz. Chim. Ital. 1989, 119, 385-388.

19. Mossa, J.S.; El-Feraly, F.S.; Muhammad, I. Antimycobacterial constituents from Juniperus procera, Ferula communis and Plumbago zeylanica and their in vitro synergistic activity with isonicotinic acid hydrazide. Phytother. Res. 2004, 18, 934-937.

20. Appendino, G.; Mercalli, E.; Fuzzati, N.; Arnoldi, L.; Stavri, M.; Gibbons, S.; Ballero, M.; Maxia, A. Antimycobacterial coumarins from the Sardinian giant fennel (Ferula communis). J. Nat. Prod. 2004, 67, 2108-2110.

21. Grande, M.; Piera, F.; Cuenca, A.; Torres, P.; Bellido, I.S. Flavonoids from Inula viscosa. Planta Med. 1985, 39, 414-419.

22. Simões, F.; Nascimento, J. Constituents of Dittrichia viscosa subsp. viscosa. Fitoterapia 1990, $61,553-554$.

23. Grande, M.; Torres, P.; Piera, F.; Bellido, I.S. Triterpenoids from Dittrichia viscosa. Phytochemistry 1992, 31, 1826-1828.

24. Grande, M.; Bellido, I.S. 9-Hydroxynerolidol and bicyclic sesquiterpenoids from Dittrichia viscosa. J. Nat. Prod. 1992, 55, 1074-1079.

25. Pérez-Alonso, M.J.; Velasco-Negueruela, A.; Duru, M.E.; Harmandar, M.; García Vallejo, M.C. Composition of the volatile oil from the aerial parts of Inula viscosa (L.) Aiton. Flavour Fragr. J. 1996, 11, 349-351.

26. Camacho, A.; Fernández, A.; Fernández, C.; Altarejos, J.; Laurent, R. Composition of the essential oil of Dittrichia viscosa (L.) W. Greuter. Riv. Ital. EPPOS. 2000, 29, 3-8.

27. Oka, Y.; Ben-Daniel, B.H.; Cohen, Y. Control of Meloidogyne javanica by formulations of Inula viscosa leaf extracts. J. Nematol. 2006, 38, 46-51.

28. Alexenizer, M.; Dorn, A. Screening of medicinal and ornamental plants for insecticidal and growth regulating activity. J. Pest. Sci. 2007, 80, 205-215.

29. Mansour, F.; Azaizeh, H.; Saad, B.; Tadmor, Y.; Abo-Moch, F.; Said, O. The potential of Middle Eastern flora as a source of new safe bio-acaricides to control Tetranychus cinnabarinus, the carmine spider mite. Phytoparasitica 2004, 32, 66-72.

30. Cafarchia, C.; De Laurentis, N.; Milillo, M.A.; Losacco, V.; Puccini, V. Fungistatic activity of a sesquiterpene lactone (tomentosin) isolated from fresh Inula viscosa (Asteraceae) flowers from the Puglia region. Parassitologia 2001, 43, 117-121. 
31. Cafarchia, C.; De Laurentis, N.; Milillo, M.A.; Losacco, V.; Puccini, V. Antifungal activity of essential oils from leaves and flowers of Inula viscosa (Asteraceae) by Apulian region. Parassitologia 2002, 44, 153-156.

32. Berdicevsky, I.; Duek, L.; Neeman, I.; Maoz, M. Antimycotic activity of tayunin-Inula viscosa extract-SEM observations. In 41st Interscience Conference on Antimicrobial Agents and Chemotherapy, Chicago, IL, USA, 16-19 December 2001; Abstract Number J-98.

33. Maoz, M.; Neeman, I. Effect of Inula viscosa extract on chitin synthesis in dermatophytes and Candida albicans. J. Ethnopharmacol. 2000, 71, 479-482.

34. Qasem, J.R.; Al-Abed, A.S.; Abu-Blan, H.A. Antifungal activity of clammy inula (Inula viscosa) on Helminthosporium sativum and Fusarium oxysporum f. sp. lyccopersici. Phytopathol. Mediterr. 1995, 34, 7-14.

35. Abou-Jawdah, Y.; Wardan, R.; Sobh, H.; Salameh, A. Antifungal activities of extracts from selected Lebanese wild plants against plant pathogenic fungi. Phytopathol. Mediterr. 2004, 43, 377-386.

36. Cohen, Y.; Baider, A.; Ben-Daniel, B.H.; Ben-Daniel, Y. Fungicidal preparations from Inula viscosa. Plant Prot. Sci. 2002, 38, 629-630.

37. Wang, W.Q.; Ben-Daniel, B.H.; Cohen, Y. Control of plant diseases by extracts of Inula viscosa. Phytopathology 2004, 94, 1042-1047.

38. Cohen, Y.; Wang, W.Q.; Ben-Daniel, B.H.; Ben-Daniel, Y. Extracts of Inula viscosa control downy mildew of grapes caused by Plasmopara viticola. Phytopatology 2006, 96, 417-423.

39. Oka, Y.; Ben-Daniel, B.H.; Cohen Y. Nematicidal activity of powder and extracts of Inula viscosa. Nematology 2001, 3, 735-742.

40. Özcan, M.M.; Chalchat, J.C.; Arslan, D.; Ates, A.; Ünver A. Comparative essential oil composition and antifungal effect of bitter fennel (Foeniculum vulgare ssp. piperitum) fruit oils obtained during different vegetation. J. Med. Food. 2006, 9, 552-561.

41. Németh, É. Changes in Essential oil quantity and quality influenced by ontogenetic factors. Acta Hort. 2005, 675, 159-165.

42. Topçu, G.; Öksüz, S.; Shieh, H.L.; Cordell, G.A.; Pezzuto, J.M.; Bozok-Johansson, C. Cytotoxic and antibacterial sesquiterpenes from Inula graveolens. Phytochemistry 1993, 33, 407-410.

43. Máñez, S.; Recio, M.C.; Gil, I.; Gómez, C.; Giner, R.M.; Waterman, P.G.; Ríos, J.L. A glycosyl analogue of diacylglycerol and other antiinflammatory constituents from Inula viscosa. J. Nat. Prod. 1999, 62, 601-604.

44. Hernandez, V.; Del-Carmen-Recio, M.; Máñez, S.; Prieto, J.M.; Giner, R.M.; Rios, J.L. A mechanistic approach to the in vivo anti-inflammatory activity of sesquiterpenoid compounds isolated from Inula viscosa. Planta Med. 2001, 67, 726-731.

45. Yegen, O.; Berger, B.; Heitefuss, R. Investigations on the fungitoxicity of extracts of six selected plants from Turkey against phytopathogenic fungi. J. Plant Dis. Prot. 1992, 99, 349-359.

46. Abou-Jawdah, Y.; Sobh, H.; Salameh, A. Antimycotic activities of selected plant flora, growing wild in Lebanon, against phytopathogenic fungi. J. Agric. Food Chem. 2002, 50, 3208-3213.

Sample Availability: Samples of the compounds are available from the authors.

(C) 2011 by the authors; licensee MDPI, Basel, Switzerland. This article is an open access article distributed under the terms and conditions of the Creative Commons Attribution license (http://creativecommons.org/licenses/by/3.0/). 